\title{
Inclusion of Excluded: Integrating Need Based Concerns of Hijra Population in Mainstream Development
}

\author{
Noorie Safa \\ Gender Justice and Diversity, BRAC, Bangladesh
}

Copyright $\subseteq 2016$ by authors, all rights reserved. Authors agree that this article remains permanently open access under the terms of the Creative Commons Attribution License 4.0 International License

\begin{abstract}
Existing binary of boys vs. girls, men vs. women, creates a boundary which restricts us to think out of box. Consequently, within a box when we fix socially constructed men women image, intentionally we miss out diversity aspects. Nevertheless, putting intersectional lens when gender theme is explored in broader spectrum, that sprout out concerns of marginalized groups be it related to their gender identity or to sexual orientation. It is needless to say concern of hijra population is a serious issue because of prevailing silo in society with regards to their rights. Emphasizing on reciprocal relationship between gender and power, this study endeavored to identify need based concerns of hijra population those are likely to integrate them in mainstream development. To identify needed initiatives for hijra people, besides mapping out existing Government and NGO initiatives, attention was also given on capturing real life scenario of this excluded pool of population. This qualitative study focused on both primary and secondary sources. Following purposive sampling, beside life history method, 10 in-depth interviews and three FGDs were employed. Analyzing existing gaps and needs of this particular group the study concluded that to include this excluded hijra population in mainstream society, mere concentration of sexual health or state sponsored stipend provision would not add any value unless and until initiatives are taken on the ground of hijra people's human right concern. By pointing out needed initiatives, the paper ended up with the suggestion of strengthening strong coordination between Government and NGOs to leverage the potentials of this marginalized hijra population.
\end{abstract}

Keywords Intersectional Lens, Gender Identity, Exclusion-inclusion, Government and NGO Initiative, Need Based Approach, Human Right

\section{Introduction}

When a particular category is labeled as 'normal' ; that simultaneously opens up opposite category labeled as 'deviant' ${ }^{\text {' }}$; and anything that is socially labeled as 'deviant' is liable to be punished or to be hatred unless and until it gets ' normal' as per social expectation'. To support this statement, dominant social ideologies of masculinity and femininity those engrave the concept of 'real men' and 'real women' can be focused. In this society stereotypical 'ideal men' get associated with traits like independent, non-emotional, aggressive ,competitive ,strong, experienced, active, self confident, hard and 'ideal women' get associated with traits like dependent, emotional, quiet, weak, nurturing, soft. It is noticeable that a person has to go through tremendous social pressure in case of deviation from culturally expected gender identity ${ }^{2}$ which is set in accordance to that person's biological sex. In this respect, a Hijra $^{3}$, who is traditionally considered as neither men nor women, senses such structural pressure to an extreme level.

It is to be noted that our most emphasized concern over men women issue mostly excludes diversity aspects. However, when gender theme is explored through intersectional lens that brings out concerns of marginalized groups be it related to their gender identity or to sexual orientation. It is needless to say amid all marginalized groups, concern of Hijra population should be highlighted as human right issue, which is ruthlessly ignored in mainstream society.

Most official records suggest that the number of Hijra people in Bangladesh is around 10,000 ${ }^{4}$. Although many rights groups estimate there are half a million Hijras in Bangladesh who face stigma and discrimination ${ }^{5}$ in every walk of life. Hijra community in Bangladesh faces manifold

\footnotetext{
1 In sociology deviance describes an action or behavior that violates social norms, including a formally enacted rules, See:http://en.wikipedia.org/wik i/Deviance \%28sociology\%29

2 Gender Identity is an individual's internal sense of being male, female, or something else. Since gender identity is internal, one's gender identity is not necessarily visible to others. See:http://transequality.org/issues/resources/tr ansgender-terminology

3 Hijra is a term used in South Asia. According to Habib (2012) hijra could be identified as 'a person who is born as male or ambiguous genital sex, often put themselves in women's role and approach as women

4S e e :http://opinion.bdnews24.com/2014/01/15/beyond-hijra-recognition-f or-transgender-bangladeshis/ (accessed 02 December 2014)

5 S e e : http://www.dailymail.co.uk/news/article-2829481/Transgender-Ban gladeshis-hold-Dhaka-s-pride-parade-mark-year-official-recognition-gende r.html (accessed 02 December 2014)
} 
challenges to maintain their identity in the mainstream society. Since the British period till today, in the context of Bangladesh, the gender and social roles of the hijra community have continued to be discriminated through the social value and legal framework. In addition, the Hijra population has often been stigmatized by the heterosexist norm of the society (Godwin, 2010). In mainstream society Hijra people are feared; tabooed and excluded as they are considered as 'social misfits'. The transgender or Hijra people hardly enjoy any rights as a human or as a citizen of Bangladesh. They lack the opportunities to get formal education, employment and are often denied the rights to seek for general medical attentions. Hijra whether doing the traditional work or sex work, they often seek their sexual partner with whom they want to spend their entire life, however, the crucial reality is that they never find their faithful life partner in this heterosexist norm and are often misused by this mainstream society where they are usually forced to have unsafe sex and live in a risk of HIV tendency (Khan et al, 2009). It is evident that transgender people belongs to high risk groups of having STI, HIV/AIDS infections. Stigma, discriminatory laws, social exclusion and a general lack of understanding about transgender issues make it extremely difficult for transgender people to protect themselves from HIV infection ${ }^{6}$.A basic right such as accommodation is also inaccessible for hijra community in the mainstream society (Josim, 2012). Even the death of hijra does not end their disgrace and different religions and social norms complicate the matter of burying the body and conducting the funeral. (Habib, 2012).

While the hijra community is excluded from the mainstream social life, the civil society is not giving enough attention to this issue. (Habib, 2012). It goes without saying that due to lack of support mechanisms stretched towards TG community followed by both government and NGOs, a culture of silo gets entrenched in society which merely restricts TG community to enjoy their minimal human rights. In spite of all these obstacles and negativity we believe there is light behind darkness because it is not hard to think by extending united and coordinated supports, if both government and development organizations become sincere and sensitive about TG community's human rights issue and integrate their concern in mainstream development, a positive impact on this vulnerable portion of the community will be evident.

\subsection{Objective of the Study}

The justification of the study was derived from the need of identifying some major concern areas those are likely to integrate hijra population in mainstream development. It is to mention, to map out possible concern areas, there was a dire need to understand real life scenario of this particular group. In addition, this study tried to address initiatives those have been taken by Government and Non-governmental

6 See: http://www.avert.org/transgender-hiv.htm\#sthash.RaQpCoVj.dpuf (accessed 02 December 2014)
Organizations to fight this social challenge. Identifying existing gaps of ongoing initiatives, this paper finally comes up with some need based concerns of hijra population aim at fostering their involvement in mainstream development.

So, the research was concerned with the following objectives-

\section{Main Objective}

To identify need based concerns of Hijra population those are likely to pave their way towards mainstream development.

\section{Sub Objectives}

- To capture the real life scenario of Hijra people;

- To map out existing initiatives of Government and Non-governmental Organizations for Hijra population;

\subsection{Methodology}

As the purpose of the study was to mapping out need based concerns of TG community, the study was designed as a qualitative one. Making the study qualitative was helpful to unveil empirical standpoint of the studied population.

Both primary and secondary sources were employed to gather pertinent information. A great deal of time has been spent to find out information in the online sources and printed versions of existing literatures- journals, news, research papers etc. After understanding conceptual issues and reviewing existing relevant literatures, the major work was to go to the ground and to collect relevant data which was likely to shape up the whole analysis and argument in a systematic order.

\section{Selection of the Samples of the Research}

Study respondents were selected through the process of purposive sampling. It is to mention, since the study was concentrated on HIjra population, all the respondents those were selected, belonged to that particular group and all of them were from Dhaka division. Heterogeneity in age was maintained, which was ranged from 18 years old to 40 years old. Total number of respondents was 18 , where 16 belonged to Guruma led 'hijra community'; and was engaged in tradition hijra profession. The study also selected two hijra right activists; those are presently working in two national Non Governmental Organizations.

\section{Methods of Data Collection}

To collect data, three important methods were used-

- Focus Group Discussion

- In-depth Interview

- Life History method

The primary information about the interviewees was taken from Focus Group Discussions. Later, further information was gathered through in-depth interview and life history method.

A total of three Focus Group Discussions were employed by keeping six people in each discussion. So the total number 
of respondents of the FGD was 18 .

While conducting FGDs importance was given to sort out interesting and informative respondents. So, after completion of the conversation total 10 were chosen as interviewees. Among the selected respondents for interview, eight of them belonged to traditional 'Hijra' profession while other two belonged to NGO profession as hijra activist. The interviews were open ended so no particular questionnaires were set. Some indications were given to carry on the interviews. For retrospective data, five informants were selected and through employing life history method, their experience ranging from childhood to adulthood was gathered.

\subsection{Limitations}

- Lack of secondary source based information regarding hijra issue from Bangladesh perspective;

- Insufficient information in concerned NGO's website related to their intervention for hijra population;

- Sole focus was on transvestites ${ }^{7}$ and transsexuals ${ }^{8}$, as interse ${ }^{9}$ hijra was not found anywhere

\section{A Glimpse of Real Life Scenario of Hijra Population}

By analyzing retrospective data gathered through empirical standpoint of study informants, this section comes up with real life scenario of hijra people, ranging from childhood to adulthood. In four broader points the life scenario has been presented-

\subsection{Development of Feminine Psyche: Results in Pathetic and Exploitative Childhood}

Early childhood preference of a hijra mostly goes for female clothing, make-up and attire, playing with girls rather than with boys, preferring household work culturally assigned for females, and possessing a 'soft' nature like girls, that makes all the family members tensed as they expect boys to portray ' boy like' image.

Most of hijra believe that oppression and discrimination against them incept from family. According Kajol hijra-

'Discrimination and humiliation starts from supposed to be the most comfortable social institution-' Family'! As I was born with male genital organ, society immediately termed me as boy. Based on my biological organ, it started teaching me what should be my gender identity. But as I grew up I

7 A person who wears clothes traditionally worn by and associated with the opposite sex; typically a male who cross-dresses occasionally by habit or compulsion.

8 Transsexualism is when an individual with a gender inconsistent or not culturally associated with their assigned sex, i.e. in which a person's assigned sex at birth conflicts with their psychological gender

9 intersex refers to individuals born with both male and female genitalia became more comfortable with what it goes for opposite gender. Due to this fact all the time I got pointed out by my family members and was blamed for tarnishing family image. In my broken heart sometimes I ask myself that all my capacities and talents got ignored as my mere gender identity becomes the major criteria of justifying me!'(Kajol, 18years old)

The humiliation and violence against unusual feminine boy not only limited in family sphere but also in every possible social institution. In this study, all the informants were found to attend in school in early childhood in spite of their belonging to low economical social class. All of informants reiterated that how cruelly they used to be humiliated by their classmates and teachers because of their incompatible feminine attitudes. Moyna hijra stated in this regard-

'In my school I was considered as an object of entertainment for rest of the class. My mates used to make fun out of me because of the feminine attitude. Most of the time I felt excluded as none of my mates, be it girl or boy, ever comfortably accepted me while playing or sharing any joy' (Moyna,20 years old)

Most of the informants said that as they could not get adjusted with hostile school environment, at one point or another they discontinued schooling which ultimately diminished their future employment opportunities.

While reminiscing about childhood memories, most of respondents became emotional while describing how badly they were used to be alienated from enjoying minimum human rights.

\subsection{Ambivalent Self Identity: Results in Turbulence and Dilemma in Early Adolescent Period}

After hazardous childhood, when feminine boys entered in adolescent age they face different sorts of psychological trauma. The study found that during the early adolescent period the growing sense of helplessness first pushed them to get oriented with the Hijra community. Although at this point they did not leave the family, but they started frequent movement to build relationship with the peer group which sometimes lead them to maintain two different lifestyles.

'Underneath male body, the existence of female soul could not restrict me in maintaining two different lifestyles in and outside the home, during my adolescent period' (Nupur, 28 years old)

By mentioning about two different lifestyles, Nupur basically indicated that while being with family, to fulfill social expectations she used to dress like men, then again while visiting peers she used to wrap herself with feminine cloths. Similar experience was reported from almost all the respondents. Some of respondents also reported that while being with peer groups, they used to adopt feminine names 
but after coming back home they used the name that was given by family. All of the informants got agreed with the fact that the frequent practice of maintaining two different lifestyles basically creates a dilemma in their inner soul which basically ended up by whispering a question to thyself 'who am i?'

With the physical growth, sexual maturation also takes place during the puberty. Most of the respondents came to one certain point that during the puberty sudden change in body structure and growing sexual aspiration lead more complication in life. As their sexuality and sexual behavior do not comply with their biological sex, that ultimately grow a sense of marginalization to a certain level. Most HIjra described, as they grow up, their attraction towards man grows up significantly, which sometimes results in love relationship with their male partners whom they term as 'Parik'. With a hope of staying with Parik throughout the life, although Hijras initiate love relationships with them, however in reality these relationships do not sustain further. As described most of the time Parik grow relationship out of their own need of amplifying sexual pleasure, so when the need is over, they just throw out the emotional bonding and put an end. While describing the experience of first physical intercourse, most of respondents said that at the age of 12-15, they first develop sexual relationship with their male tutor, neighbor or even with relatives. According to respondents in majority of cases such initial intercourses happen by force. Due to lack of knowledge on the danger of HIV infection, most of these forced sexual relationships leave them at the risk of STI/HIV.

Dominant hetero normative culture, which is fueled by dichotomous gendered norms, further grows sense of exclusion among adolescent transgender people. All these crises intensify their worrisome in defining their gender identity.

\subsection{In Search of Freedom: Results in Amalgamation with Hijra Community}

Heinous life experience of hijra people in their childhood and early adolescent period leaves a deep arch in soul which makes them more vulnerable in late adolescent period; as with the course of time they realize dichotomous gendered society curtails their freedom in all aspects of life. Confrontation and conflict with family members continues with regard to their feminine behavior and attitude. To maintain respect of family, most often family members exclude them from any cultural event and even from funeral. A state of being alienated continues despite being connected to a family. Although in initial adolescent period many hijra get connected with their peer community, but generally during that time they do not get the courage of leaving family. However, the decision of leaving home get finalized when they feel staying home will neither give them psychological comfort nor will allow them to earn the livelihood by getting integrated with the mainstream society.

According to informants, most of hijra leave their family and join the hijra community between $15-18$ years, and among them maximum belong to low economical class.

'All the hijras those leave home and look for hijra
community, basically hail from low socio
economical status. In rich family although hijra born
but to maintain family respect they hardly leave the
attachment; to satisfy their natural instinct they
usually do cross dressing during night. However,
people like me those come from lower socio
economical class, face multiple forms of
exploitations which generally push us leave the home.
Our families neither can guarantee a minimum
standard of living due to poverty nor can ensure
comfortable space for exercising freedom of choice.
Consequently at one point with a view to ensuring
both economical and mental freedom, we look for
hijra community. (Piya, 34 years old)

So, in search of freedom they finally leave the family and get associated with hijra community. It was reiterated by all the informants that although they get separated from the family, but deep inside the hidden love for the family members haunt them abruptly!

\subsection{Involving in HIjragiri (Traditional Activities Performed by Hijra; e.g. Collecting Money, Dancing etc) and Sex Work: Results in New Form of Exclusions That Accelerate Exploitation to an Extreme Level}

Hijra community has its own unique formation. Every Hijra community is led by HIjra 'Guruma', who is considered as head of the community. When a hijra meets a hijra guru, becomes a chela of that guru. According to Habib (2012) Guru and Chela relationship always go through some disciplines and rules in their community. One of respondents, named as Rupa Hijra stated about the significance of living in Hijra community-

'Guruma lead Hijra community in one way support the chela to be with likeminded people and in another way give them the scope to earn some money through hijragiri and sex work' (Rupa,27 years old)

Being curious about the term 'hijragiri' when inquisition was focused to get deeper understanding about it, some interesting information came out. According Habib (2012),Hijragiri is considered as collecting money through blessing new born babies by singing and dancing called 'Baccha Nachano'. Another traditional work is collecting money from the shops in the markets called 'Bazar Tola'.

According to respondents, after joining with hijra community most of chelas get engaged with hijragiri and through this traditional occupation they earn their livelihood. While discussing with informants, it came out that beside hijragiri, a large number of hijra people are engaged in sex work profession. No matter whether they are engaged in hijragiri or sex work, whatever money they earn through 
these traditional works, they have to hand over the half of it to the Guruma, in return guruma takes care of them.

It is true that hijra community led by Guruma ensures certain level comfort and little extent freedom among chelas; however question can be posed whether this guru-chela dependency is creating newer forms of exploitations for the hijra population?

According to most of informants, by capitalizing hijra chelas, Guruma is accumulating huge amount profits. So it is a matter of great concern to what extent Guruma will accept when initiatives will be taken to engage hijra population towards mainstream development! According to Joya Sikder, the president of Samporker Naya Shetu, as long as hijra communities led by Guru ma exists, the chelas from the subsequent community would hardly avail any facilities provided by development programs those are aimed at integrating HIjra people in mainstream society.The foremost reason behind the fact is although initial safety and security for chelas is provided by Guruma, but by capitalizing hijra chelas, Guru Ma get benefitted in long run, as half of earned money through hijragiri is handed over to the Guruma. So, diverting form traditional hijra giri to mainstream workforce can pose serious challenge for the existence of the traditional business.

By analyzing life experience of hijra people; starting from childhood-adolescent- adulthood; it becomes apparent that in none of stages they are free from the subject of being humiliated, violated or discriminated; and it goes without saying such exclusion is the exact reason behind their chronic disempowerment.

\section{Towards Addressing Concerns of Hijra Population: Existing Government and NGO Initiatives}

This section aims at mapping out initiatives taken by Government and Non-governmental Organizations for hijra population, who got the official recognition of 'Third Gender' by Government of Bangladesh on $11^{\text {th }}$ November, 2011.At the end of the session some of challenges and shortcomings of existing program have also discussed.

While mapping out existing initiatives, it was found that under the broader LGBT issue, keeping hijra concern as secondary emphasize, negligible number of NGOs have been operating their actions. In this regard some of mentionable NGOs are- Bondhu Social welfare society, Hasab, Badhon, Shomporker Naya shetu, iccddr,b etc. Beside nongovernmental organizations, the Government of Bangladesh has also taken some initiatives for this socially excluded group after recognizing them as third gender. According to the website of Ministry of Social Welfare, ${ }^{10}$ Government has taken inevitable initiative to materialize "Program for improving the living standard of

10 See:http://www.dss.gov.bd/index.php?option=com_content\&view=articl e\&id=165\&Itemid=153 the Hijra community". In the 2012-2013 fiscal years, the rehabilitation program was primarily launched in seven districts of the country which include Dhaka, Chittagong, Bogra, Dinajpur, Patuakhali, Sylhet and Khulna. In 2013-2014, 14 more districts were included (Areas included Dhaka, Chittagong, Bogra, Dinajpur, Patuakhali, Sylhet, Khulna, Rajbari, Netrokona, Gazipur, Chadpur, Lakhhipur, Brahmanbaria, Comilla, Jhinaidah, Kushtia, Pirojpur, Jaipurhat, Serajganj, Naogaon and Faridpur) under the development program. According to the Website, in current fiscal year around 4,07,31,600 (Four crore, Seven Lakh, Thirty One Thousand Six Hundred) taka has been allotted for this under-privileged group.

After analyzing the initiatives taken by Government and NGOs, some thematic areas where they are contributing to have been sorted out, these are given below-

\subsection{Scholarship for the Hijra Children}

With a view to preventing hijra student's dropout from school, Ministry of social welfare has been providing stipends for hijra children. In 2012-2013 fiscal year, 135 students and in fiscal year 2013-20214, 762 students received stipends. According to ministry of social welfare website, in 2014-15 fiscal years, total 1199 students will receive education scholarship.

\subsection{Training for Skill Development}

As a part of developing technical skills of Hijra population, under the governmental project a number of hijra are receiving skill based training. In 2012-13 fiscal year 350 Hijras who are 18 above got training to improve their skills. Again, in 2013-14 fiscal years, about 950 Hijras above 18 years were trained. In 2014-15 fiscal year it is estimated that after training 20 (twenty) Hijras per district (from overall 14 districts), will get taka 10,0000/- (ten thousand) per head as rehabilitation grant and beneficiaries.

\subsection{Old-age Allowance for the 50 and above}

Providing old age allowance for hijra population was one of great initiatives by Government of Bangladesh. Through governmental development program allocated for Hijra population, about 1071 Hijra's received the old age allowance in 2013-14 fiscal years. According to the website of social and welfare ministry of Bangladesh, in 2014-15 fiscal year 1725 hijra people will receive the old age allowance.

\subsection{Sexual Health Care Service}

Sexual health issue of hijra population has been identified as one of important concerns by most of NGOs working on LGBT right, as a big part of hijra population is engaged in traditional sex work. As high risk sexual behavior such as low condom use, sex with multiple partners, high client 
turnover, and low levels of risk perception is likely to increase the chance of getting affected by sexually transmitted infections (STI) among hijra population, thus most of $\mathrm{NGO} / \mathrm{CBO}$ are providing health service regarding HIV/STI prevention to hijra population. According to informants, some NGOs are also providing voluntary testing and counseling service to a little extent.

\subsection{Identified Challenges}

Although undertaken initiatives by NGO and Government have been addressing some concerns of hijra population, however questions can be posed whether these initiatives are being effective in pointing out core problematic areas of this vulnerable group? While roaming around secondary sources to capture governmental and NGOs initiatives for hijra population, starting from Ministry's website to national NGO's website, mere quantitative values were reflected those basically portrayed how many hijras had been covered under the development programs targeted for hijra population. It is noteworthy to mention that beside quantitative value, importance of capturing qualitative issues should also appear onscreen.

In terms of selecting beneficiaries, governmental programs are facing challenges. As discussed with Joya; president of Shamporker Naya Shetu, it becomes apparent that to erase ambiguity in deciding who is 'real hijra'governmental projects have been emphasizing on hermaphrodite or intersex- to be the main beneficiary of these projects. Although in reality number of intersex people is significantly low. Again, projects aimed at providing stipend to hijra children is also facing remarkable problem in identifying hijra. As stated by Joya Sikder-

'In the initial stage, it is quite difficult to identify any child as hijra, because in the early age, the child himself cannot feel about his own gender identity. If we look at governmental initiative of providing stipend to hijra children, most of the time the problem of identifying any child as hijra gets apparent. Again, in case of providing skill based training for hijra, hermaphrodites are considered to be real hijra thus considered to be eligible of being beneficiary. But if we look at hijra community we will hardly find intersex hijra but mostly as transvestites. Being transvestites does not mean they are unreal hijra, since in majority cases it comes from core!' (Joya, 32 years old)

Yet again, if we look at services provided by Non Governmental Organizations, we find sheer focus is given on providing sexual health care services. But question can be posed, by ignoring right based concern and the need of sensitizing broader society, if sole concentration is given on sexual health issue will that bring sustainable development and positive empowerment among this marginalized group? Leaving no doubt, the answer will be 'NO'!It is high time to expand the range of services for hijra in inclusive, strategic and coordinated manner.

\section{Towards Inclusive Approaches: Needed Initiatives to Mainstream Hijra Population}

Although recognizing Hijra as third gender is a breakthrough policy decision, but to attain the underlying significance of the provision, still there is a long way to go. It is needless to mention that by the virtue of being human and being legitimate citizen of Bangladesh as well, every hijra is entitled to enjoy all the rights preserved by the constitution; nevertheless due to lack of strategic and coordinated actions by Government and NGOs, manifold vulnerabilities of this specified group persists alarmingly. Considering existing challenges, this section aims at unfolding some crucial issues those should be focused to integrate hijra concerns in mainstream development.

It is already reflected in previous section that ongoing Governmental and NGO initiatives for hijra population pose multiple shortcomings, as these ignored crucial needs of this marginalized group and failed to operate in coordinated and inclusive manner. By analyzing needs of this vulnerable group, some crucial concerns where development project should give more rigorous concentration are discussed below-

\subsection{Establishing Psycho-social Counseling Center for Hijra Population}

It is assumed that a sound mind gives a person the strength of utilizing the inner capacity at its fullest. However, the productivity goes down automatically when that individual has to go through a coarse path. Again, it is needless to say the situation gets much worse when the person does not get any space to vent out the inner pain. Realizing this fact, if we consider life cycle of any individual born with so called 'deviant gender identity', is likely to be the subject of mere humiliation, discrimination and violence. In this respect, when Hijra people's experience is posed that basically reveals how these people eventually diminish their own potentials being the subject of humiliation and discrimination.

To rescue this potential social pool from the risk of being demoralized, it is obligatory to form national psycho social counseling center, which will provide rigorous counseling sessions for them to boost up their inner capacity. This counseling session is required in both individual and family level. As the violence against hijra people primarily starts from family level, it also essential to orient family members regarding how to deal with them. Through psycho social counseling center, diversified training sessions could also be arranged for Hijra people, so that they will be aware about their human rights and can be able to sprout out their inner capacity. 


\subsection{Sensitizing Primary and Secondary Level School Governing Body}

As in earlier section it was revealed that, after experiencing family level violence, when children with so called ' abnormal gender identity' enters in school level, face newer forms of violence, as none of teachers or class mates leave them from the chance of being humiliated and discriminated. During conducting FGD it was revealed that many mainstreams educational institutions hesitate to admit children belonging to so called 'unusual gender identity' as their presence might create the feelings of discomfort to other students. Although governmental project is providing stipend for hijra children to continue their study, but if we think logically we will find the aim of retaining this kind of children in school will not be sustainable through stipend provision unless and until initiatives are taken to sensitize the broader school environment. So development projects should focus on sensitizing school governing body by arranging awareness rising training session, so that among them the sense of treating every child equally irrespective of all diversities will be grown. The governing body should be consists of principles, teachers and other associated responsible people. Quarterly meeting with parents should also be arranged for sensitization. A complain box in school can also be hanged; where anyone subject to discrimination can issue complain.

\subsection{Integrating Concept of 'Diversity and Inclusiveness' in Primary and Secondary Text Book}

The culture of employing positive attitudes towards hijra people will be automatically grown up if the learning hits people's core from the very early hood; and in this respect it is important to integrate the concept of diversity and inclusiveness in school textbooks. In ongoing primary and secondary level textbooks, insignificant attention has been given towards the issue of diversities, consequently when anyone from so called 'deviant gender identity' comes forth to be mainstreamed, eventually becomes marginalized and gets termed as 'abnormal'.

\subsection{Sensitizing Broader Society}

Although recognizing hijra as third gender has caught noteworthy political attention, the significance of this recognition will be unattainable if the broader society is not aware about the rights of Hijra population. Prevalence of poor knowledge and lack of awareness about Hijra population amid mainstream society basically multiplies incidents of violence against HIjra population to an extreme level. So campaign through media and social media platforms should be well operated which will include: the problematic socialization process of Hijra population, institutional violence towards this marginalized group, the culture of Guruma lead Hijra community, challenges towards Hijra population to be in mainstream society etc. Sensitizing the mainstream society regarding different gender identity and sexual orientation is also an essential issue. Under the ministry of information, existing departments on press information, mass communication, films and publication can play catalytic role in disseminating concerned information.

\subsection{Providing Inclusive Health Care Services}

Hijra people face multiple barriers while seeking health care services in general hospitals. As stated by one of informants of the study, the incidents of refusing to provide general health care service to hijra people frequently take place, even though the motto and approach of providing health care service should be inclusive to all people of all gender identity. Due to this obstacle in general hospitals, Hijra people basically feel comfortable to go national NGOs where their concerns are treated with respectful manner. But it is a matter of great concern that these NGOs basically provide sexual health related supports having prime focus on HIV/STI related preventative measures. Although the risk of being affected by HIV/STI is higher among hijra population basically among those are engaged in sex work, but definitely it does not necessarily mean Hijra people do not need general health care services. Some of informants reiterated that in hospitals at times if they somehow manage to seek health care service, some unavoidable issues create certain level of discomforts, for instance, medical history form that include only male and female and non availability of unisex toilets can be mentioned. So it is one of requisites to ensure gender health care services for hijra population. Starting from nurse to senior medical doctors, everyone has to be sensitized about the right of Hijra population in receiving health services like all people in society.

\subsection{Incorporating Transgender Concern in Organizational Policy Mandate}

Holding firm stance in recognizing diversity aspects, both Governmental and Non Governmental Organizations should show pro activeness in considering workplace diversity; and driven by this ideological standpoint, every organizational policies should be reviewed such a way that respect every human being irrespective of any divergence. Followed by this unique inclusiveness approach, it is vital to incorporate concerns of hijra population in organizational policy mandates. Now question can be raised in which areas organizational policies should give more concentration?

First of all, the provision of allocating certain percentage of posts for hijra people can be operated. Yet again, the opportunity of receiving special skill based training can be arranged for hijra staff after the recruitment process. If we look at right based NGOs, we see by providing diversified training platforms through multiple projects, these organizations sensitize community as well as its own staffs with regard to human right issue, gender and legal concerns etc. It is needless to say in all relevant training modules, those flourish human rights concern, transgender concern 
needs to be incorporated. It is likely that in broader arena if community people internalize the right of Hijra population that will simultaneously lessen social stigmatization directed towards this socially marginalized group. Again, while designing project proposals or program design, under the broader gender spectrum transgender concern can be included.

Holistic approaches are required for the sustainable development of Hijra population. Through coordinated way different ministries of Bangladesh; e.g. ministries focused on social welfare, education, health and family welfare, primary and mass education, labour and employment, law justice and parliamentary affairs; can integrate hijra concerns in ongoing programs and projects. Allocated national budget for technical skill development for hijra should be increased and in this regard a robust follow up mechanism should be well maintained to track out training outcome. It is crucial to prioritize hijra in social safety net programs; e.g. Vulnerable Group Feeding (VGF), Vulnerable Group Development (VGD), medical allowance, rehabilitation, micro credit scheme, swanirvar training program; operated by ministry of social welfare.

\subsection{Strengthening Advocacy and Networking}

To blow strong movement, it is obligatory to establish a strong alliance with organizations working on transgender issues in both national and transnational level. It is noteworthy to mention that through rigorous advocacy and networking support mechanism the vision of advancing the situation and condition of hijra population will be fostered. Vigorous lobby with Government should be promoted to pave the way for negotiation with Government. With the power of strong lobby, strong push with regard to formulating and changing policies, laws and regulations more easier.

\subsection{Conducting Study on Transgender Issue}

Negligible number of literature and research work on hijra population signifies that the concern of this marginalized section is hugely ignored in both academic and practitioner level. It becomes an integral need to conduct thorough research on state sponsored third gender, to get exquisite understanding about their current condition and position in society. By capturing learning, future possibilities for Hijra people will be opened up.

Considering all of mentioned concerns, pro active initiatives need to be taken as early as possible and in this regard strong coordination between Government and NGOs should be well maintained. But it is to be in mind transformative initiatives is likely to pose serious challenge in the existence of Guru ma led hijra community, surrounding which big business has been established and such situation might results in reversed outcome during project implementation. But it is true that, saving this marginalized group from the loop of chronic disempowerment will not be possible as long as they belong to guruma led hijra community and engage in traditional hijra profession by leaving the family and ignoring all the possible scopes of being mainstreamed. So in this regard, strong political intervention of Government is required.

\section{Concluding Remarks}

When we say about gender we should consider the issue of power dynamics and when we look on power dynamics we should visualize a ladder to envisage who is on top or on lower tier. It is needless to say due to the social, cultural and economic reality women are the poorest of the poor which make them more vulnerable in terms of getting equal treatment with men, nevertheless if we dig more and look through intersectional lens, vulnerability of diverse sections will also be popped out those also warrant serious consideration. On the basis of this rational, the study was conducted on state sponsored third gender, and the study findings show a way out with regard to bringing this marginalized group of people in mainstream development. With a view to including this excluded hijra population in mainstream society, mere concentration of sexual health or state sponsored stipend provision would not add any value unless and until initiatives are taken on the ground of hijra people's human right concern. It is believed that sincere attention and intervention of Government and NGOs with regard to ensuring hijra people's human right would certainly bring positive outcome in broader society. It is high time to blow strong movement with an aim to letting this excluded yet fully potation pool of society to live with dignity and respect.

\section{REFERENCES}

[1] Bondyopadhyay, A. and Ahmed, S. ed., 2010. SAME-SEX LOVE IN A DIFFICULT CLIMATE: A study into the Life Situation of Sexual Minority (Lesbian, Gay, Bisexual, Kothi and Transgender) Persons in Bangladesh. Dhaka: Bandhu Social Welfare Society.

[2] Bornstein, K 1997, My gender workbook, NY, Routledge

[3] Brown, M L \& Rounsley, C A 1996, True selves : Understanding transsexualism-for families, friends, coworkers, and helping professionals, San Francisco, Jossey-Bass

[4] Chakrapani, Dr. V. (2010). Hijras/Transgender Women in India: HIV, Human Rights and Social Inclusion. United Nations Development Programme (UNDP), India.

[5] Girshick, Lori B. (2008). Transgender voices: beyond women and men. Hanover, N.H.: University Press of New England.

[6] Godwin, John (2010). Legal Environments, Human Rights and HIV responses among men who have sex with men and transgender people in Asia and the Pacific: An agenda for 
action. Bangkok: United Nations Development Programme (UNDP).

[7] Habib, T. (2012) A Long Journey towards Social Inclusion: Initiatives of Social Workers for Hijra Population in Bangladesh. University of Gothenburg

[8] Husain, S. A. M., 2005. Tritio Prokriti: Bangladesher Hijrader Arthoshamajik Chitro (Hidden Gender: A Book on socio-economic status of Hijra community of Bangladesh). Dhaka: Sararitu.

[9] Josim, T. B., 2012. Hijra: Ak omimangshito Lingo (Hijra: An unresolved Gender). Ajker Prottasha, 8 March.

[10] Khan et al., 2009. Living on the Extreme Margin: Social Exclusion of the Transgender Population (hijra) in Bangladesh. Health, Population and Nutrition.

[11] Khan et al., 2008. Not to Stigmatize but to Humanize Sexual Lives of the Transgender (Hijra) in Bangladesh: Condom Chat in the AIDS Era. LGBT Health Research.

[12] Karim, M 2013, 'Hijras Now a Separate Gender', Dhaka Tribune, viewed 02 December 2014,

[13] Nanda, Serena (1999). Neither man nor woman: the hijras of India. 2. uppl. Belmont, Calif.: Wadsworth Pub. Co.

[14] Stringer, J A 1990, The transsexual's survival guide: To transition and beyond, King of Prussia, PA, Creative Design Services

[15] Towle, R.B. and Morgan, L.M. Romancing the Transgender Native: Rethinking the Use of the "Third Gender" Concept (in Stryker, S. and Whittle, S. (2006) Transgender Studies Reader. Routledge: New York, London).

[16] Walworth, J 1999, Bellingham, Transsexual workers: An guide for coworkers, WA, Center for Gender Sanity.

[17] http://en.wikipedia.org/wiki/Deviance \%28sociology\%29
[18] http://www.dailymail.co.uk/news/article-2829481/Transgend er-Bangladeshis-hold-Dhaka-s-pride-parade-mark-year-offic ial-recognition-gender.html (accessed 02 December 2014)

[19] http://www.avert.org/transgender-hiv.htm\#sthash.RaQpCoVj .dpuf (accessed 02 December 2014)

[20] http://opinion.bdnews24.com/2014/01/15/beyond-hijra-recog nition-for-transgender-bangladeshis/ (accessed 02 December 2014)

[21] http://www.bandhu-bd.org/

[22] http://www.hasab.org/

[23] http://www.dailymail.co.uk/news/article-2829481/Transgend er-Bangladeshis-hold-Dhaka-s-pride-parade-mark-year-offic ial-recognition-gender.html (accessed 02 December 2014)

[24] http://www.avert.org/transgender-hiv.htm\#sthash.RaQpCoVj .dpuf (accessed 02 December 2014)

[25] http://www.dss.gov.bd/index.php?option=com_content\&vie $\mathrm{w}=$ article $\& \mathrm{id}=165 \&$ Itemid $=153$

[26] http://www.dhakatribune.com/bangladesh/2013/nov/11/hijra s-now-separate-gender

[27] http://transequality.org/Resources/TransTerminology_2014. pdf

[28] http://www.scottishtrans.org/guidance/transgender-umbrella/

[29] http://www.fenwayhealth.org/site/DocServer/Handout 7-C Glossary_of_Gender_and_Transgender_Terms_fi.pdf

[30] http://en.wikipedia.org/wiki/Transgender

[31] http://www.glaad.org/reference/transgender

[32] http://www.lawctopus.com/academike/current-scenario-third -gender/ 